\title{
Insights for the development of a functional fish product: drivers and barriers, acceptance, and communication of health benefits
}

Article

Accepted Version

De Devitiis, B., Carlucci, D., Nocella, G., Viscecchia, R., Bimbo, F. and Nardone, G. (2018) Insights for the development of a functional fish product: drivers and barriers, acceptance, and communication of health benefits. Journal of Aquatic Food Product Technology, 27 (4). pp. 430-445. ISSN 1547-0636 doi: https://doi.org/10.1080/10498850.2018.1447059 Available at https://centaur.reading.ac.uk/75945/

It is advisable to refer to the publisher's version if you intend to cite from the work. See Guidance on citing.

To link to this article DOI: http://dx.doi.org/10.1080/10498850.2018.1447059

Publisher: Taylor \& Francis

All outputs in CentAUR are protected by Intellectual Property Rights law, including copyright law. Copyright and IPR is retained by the creators or other copyright holders. Terms and conditions for use of this material are defined in the End User Agreement. 


\section{www.reading.ac.uk/centaur}

\section{CentAUR}

Central Archive at the University of Reading

Reading's research outputs online 
Running head: INSIGHTS FOR NEW FUNCTIONAL FISH PRODUCTS

1 Insights for the development of a functional fish product: drivers and barriers, acceptance and communication of health benefits

5 Biagia De Devitiis ${ }^{\mathrm{a}}$, Domenico Carlucci ${ }^{\mathrm{b}}$, Giuseppe Nocella ${ }^{\mathrm{c}}$, Rosaria Viscecchia $^{\mathrm{a}}$, Francesco 6 Bimbo $^{\mathrm{d}}$, and Gianluca Nardone ${ }^{\mathrm{a}}$

7

a) Department of Agricultural, Food and Environmental Sciences, University of Foggia, Italy

b) Department of Agricultural and Environmental Sciences, University of Bari "Aldo Moro", 10 Bari, Italy

c) School of Agriculture, Policy and Development, University of Reading, Reading, UK

d) Business Economics Group, Department of Social Sciences, Wageningen University, Wageningen, The Netherland 


\section{INSIGHTS FOR NEW FUNCTIONAL FISH PRODUCTS}

\section{Abstract}

30 This study aims to explore consumers' acceptance of a new functional fish burger by using a

31 qualitative approach based on four focus group discussions conducted in selected major

32 Italian cities. Results show that the development of functional fish products may bypass fish

33 consumption barriers combining convenience and health benefits delivered by functional

34 ingredients. The acceptance of new functional fish products seems to be influenced positively

35 by the enrichment of functional ingredients naturally present in fish, particularly Omega-3

36 fatty acids. Consumers' acceptance of this new product is also influenced by the use of

37 different nutritional and health claims. Implications for marketers, policy makers and insights

38 for further research are discussed in the conclusions.

39

40 Key words: Functional fish, Focus group, Consumer acceptance, Omega-3, Health claims

41

42

43

44

45

46

47

48

49

50

51

52 


\section{INSIGHTS FOR NEW FUNCTIONAL FISH PRODUCTS}

\section{Introduction and Background}

The term "functional food" is used generally to communicate either that this is food that may provide health benefits beyond those delivered by traditional nutrients or foods that have potentially disease-preventing and health-promoting properties (Milner, 2000, Griffiths et al., 2009). The demand for these products is growing rapidly and a recent economic report (Research and Markets, 2014) estimates the global market for functional foods to be around $\$ 168$ billion in 2013 , while it is forecast to exceed $\$ 300$ billion by 2020 . This growth is fuelled by increasing consumer health-consciousness, particularly in Western societies, technological innovation and the development of new products (Granato et al., 2010). Functional foods are mostly enclosed in the industry of dairy, confectionery, softdrinks, bakery and baby-food (Bigliardi \& Galati, 2013), while the number of functional foods included in other categories is rather low. Specifically, functional foods in the form of fish and seafood products seem to be little exploited by the food industry for two reasons.

First, the food industry has probably not yet invested enough resources on their development and second, fish consumption in general is challenged by several barriers such as high market prices (Birch \& Lawley, 2012; Verbeke \& Vackier, 2005), lack of convenience (Olsen et al., 2007; Rortveit \& Olsen, 2009) and lack of knowledge and skills in selecting and preparing fish (Brunsø et al., 2009; Carlucci et al., 2015)..

Despite these barriers, fish and seafood products may have a strong potential as functional foods for several reasons. First, fish and seafood are widely perceived by consumers as healthy foods (; Brunsø et al., 2009; Burger \& Gochfeld, 2009;; Pieniak, Verbeke \& Scholderer, 2010; Verbeke et al., 2005), and previous studies show that food products that are perceived by consumers as naturally healthy are more suitable carriers for functional ingredients (Annunziata \& Vecchio, 2011; Ares, Giménez \& Gámbaro, 2008; Bech-Larsen \& Grunert, 2003; Hailu et al., 2009; Roe, Levy \& Deby, 1999). Second, taste 


\section{INSIGHTS FOR NEW FUNCTIONAL FISH PRODUCTS}

matters in the choice of functional foods (Gilbert, 2000; Lyly et al., 2007; Pothoulaki \& Chryssochoidis, 2009; Tuorila \& Cardello, 2002; Urala \& Lähteenmäki, 2003), and consumers are rarely willing to compromise on the taste of functional foods for their health benefits (Cox, Koster \& Russell, 2004; Gilbert, 2000; Verbeke, 2006). Considering that several studies show that most consumers consider fish and seafood as tasty foods and the sensory liking of fish as one of the most important drivers of fish consumption (Birch \& Lawley, 2012, 2014; Brunsø et al., 2009; Carlucci et al., 2015; Neale et al., 2012), this aspect should be an advantage in the development of functional fish products. Finally, consumers' acceptance of functional foods may depend on the specific combination of carrier and functional ingredients and, in particular, perceived healthiness of functional foods is better when the bioactive ingredient is naturally contained in the carrier (e.g. Calcium in the milk) (Cox, Evans \& Lease, 2011; Krutulyte et al., 2011; Lampila et al., 2009). Also with regard to this aspect, fish and seafood seem to be ideal carriers for several functional ingredients because they naturally contain many micronutrients such as Omega-3 fatty acids which are very important for human nutrition (FAO/WHO, 2011).

However, while a number of studies have analysed consumers' attitudes towards functional foods of various categories such as dairy, meat, bakery, beverages, etc. (BechLarsen \& Grunert, 2003; Menrad, 2003; Siegrist, Stampfli \& Kastenholz, 2008; Sirò et al., 2008; O'Brien et al., 2012), to the authors' knowledge, only Tudoran, Olsen \& Dopico (2009) have investigated consumer attitudes towards functional fish products. They explored the effect of health benefit information on individuals' stated health values, attitudes towards functional/enriched foods, and expectations, perceptions, and intentions to purchase a new fibre-enriched fish product. They found that for Spaniards fibre and health information in fish products are not especially effective, and that the market feasibility of a "new fibre-enriched 


\section{INSIGHTS FOR NEW FUNCTIONAL FISH PRODUCTS}

103 fish product" may not differ significantly from the market feasibility of a simple "new 104 processed fish product”.

As a result, the present study aims to fill this gap by exploring the marketing

opportunity of developing a new functional fish burger that can both overcome barriers and

107 take advantage of aspects regarding fish consumption mentioned previously. In particular, the study will attempt to answer the following research questions: What are consumers' reactions towards functional fish burgers? What are the main factors positively and negatively affecting consumers' acceptance of functional fish burgers? What are the most appealing functional ingredients that could be added to fish burgers? What are the product attributes that food scientists and marketers should take into account when developing functional fish burgers?

113 What is the best way to communicate health benefits of functional fish burgers? Fish burgers were considered a good compromise to explore consumers' acceptance of this functional food category because they may represent a convenient meal option that can be sold on the market at competitive prices. In fact, from an industrial point of view, fish

117 burgers reduce waste because they can be produced using minced flesh (undervalued or

118 undersized fish products) less appreciated by consumers and, in addition, it is easy to

119 incorporate a functional ingredient into this kind of product (Matak, Tahergorabi \&

120 Jaczynski, 2015; Tahergorabi, Matak \& Jaczynski, 2015). Recent studies have focused on the

121 production of fish burgers from both marine and freshwater fish (Bochi et al., 2008; Branciari

122 et al., 2016; de Quadros et al., 2015; Di Monaco et al., 2009; Haq et al., 2013;

123 Mahmoudzadeh et al., 2010; Taşkaya et al., 2003). This explorative study is also significant because, despite the fact that the fish industry seems to be motivated in developing this product, it is not obvious that functional

126 fish burgers will be well accepted by consumers for several reasons. First, previous studies

127 showed that when fish products undergo increased levels of processing, many consumers 


\section{INSIGHTS FOR NEW FUNCTIONAL FISH PRODUCTS}

seem to perceive the modifications of the characteristics of the original product as a proportional loss of quality, safety, naturalness, healthiness and nutritional value (Altintzoglou et al., 2010; Altintzoglou et al., 2012; Carlucci et al., 2015; Debucquet et al., 2012; Loose, Peschel \& Grebitus, 2012). Second, many consumers do not appear to be knowledgeable about the specific health and nutritional benefits of fish (Altintzoglou \& Heide, 2016; Carlucci et al., 2015; Pieniak, Verbeke \& Scholderer, 2010), while high levels of this knowledge seem to be necessary for the acceptance of functional foods (Ares, Giménez \& Gámbaro, 2008; Menrad, 2003; Wansink, Westgren \& Cheney, 2005). Last but not least, the communication of health benefits to consumers may not be really effective because health and nutritional claims, compatibly with the constraints imposed by different regulations (for example, EU Regulation No 1924/2006), may not be well understood and/or not well accepted by consumers (Leathwood et al., 2007; Nocella \& Kennedy, 2012).

Over the next sections, we will illustrate the research design and the methodology used to analyse the data. We then provide and discuss results obtained from the present qualitative research. Finally, marketing and policy implications for product development together with insights for further research will be discussed in the conclusions.

\section{Methodology}

\section{Semi structured focus group discussion guide and recrun itment}

To achieve the stated research objectives, a qualitative approach based on focus group discussions was adopted. The focus group method involves organized discussion with selected groups of individuals to gain information regarding their points of view and experiences on a specific topic of research, where each group is composed of a relatively small number of participants (Powell \& Single, 1996). The main purpose of focus group discussions is to draw upon respondents' attitudes, feelings, beliefs, experiences and reactions 


\section{INSIGHTS FOR NEW FUNCTIONAL FISH PRODUCTS}

153 which are difficult to obtain by using other investigation methods such as observation, one-

154 to-one interviewees, or questionnaire surveys (Krueger \& Casey, 2014; Morgan, 1998).

The recruitment of participants was conducted by a marketing research agency that

156 ran four focus groups in September 2013 in four major cities (Milan, Bologna, Rome and

157 Bari) in order to capture possible differences between the geographic areas of North, central

158 and southern Italy. Each focus group involved eight participants who were the main person

159 responsible for food purchasing in their household and who consumed fish at least once a

160 week.

162 heterogeneous in terms of gender and age (as illustrated in table 1) because research

163 conducted on general health orientation seem to vary systematically as a function of age and 164 gender (Oakes, 2003; Roininen et al., 2001; Verbeke, 2005).

Table 1. Location, gender, and age of focus group participants.

\begin{tabular}{|c|c|c|c|c|c|c|c|c|c|}
\hline & \multicolumn{2}{|c|}{ Bari } & \multicolumn{2}{|c|}{ Roma } & \multicolumn{2}{|c|}{ Milano } & \multicolumn{2}{|c|}{ Bologna } & \multirow[b]{2}{*}{ Tot } \\
\hline & Female & Male & Female & Male & Female & Male & Female & Male & \\
\hline $18-34$ years & 1 & 1 & 1 & 2 & & 3 & 2 & 1 & 11 \\
\hline $35-54$ years & 4 & 1 & 2 & 2 & 4 & & 1 & 2 & 16 \\
\hline $55-70$ years & & 1 & 1 & & & 1 & 1 & 1 & 5 \\
\hline Tot & 5 & 3 & 4 & 4 & 4 & 4 & 4 & 4 & 32 \\
\hline
\end{tabular}

Focus group discussions were carried out on the basis a pre-tested protocol that allowed researchers to collect semi-structured data (Table 2). The protocol was developed after having conducted a literature review, two interviews with practitioners working in the Italian fish industry, a pilot focus group and discussions between the authors.

173 discussion on drivers and barriers of fish consumption in general. The second section focused on specific drivers and barriers of conventional fish burger consumption with no reference to any enrichment with functional ingredients. Participants were shown photos of conventional 


\section{INSIGHTS FOR NEW FUNCTIONAL FISH PRODUCTS}

176 fish burgers and were asked to express their attitudes towards attributes of this product. The

177 third section explored participants' acceptance of fish burgers with added functional

178 ingredients that provide health benefits. Participants were asked to specify the functional

179 ingredient that they would like to fortify and discuss attitudes and motivations of their choice.

180 To help participants with this task the moderator distributed a table containing information on

181 functional ingredients that could be added to fish burgers. The selection of these functional

182 ingredients was previously discussed with academic experts in food technology and dietetics.

183 The final section attempted to understand how to communicate health benefits by showing

184 participants selected health and nutritional claims that could be used on the packaging of

185 functional fish burgers. Because the study was conducted in Italy, the discussion focused on

186 consumer understanding of health and nutritional claims released by EFSA (European Food

187 Security Agency) in May 2012 (Reg. No 432/2012). Participants were asked to reflect on the

188 meaning of the various claims, to express their preferences, and to explain the reasons for

189 their choice.

190

Table 2. Focus group protocol.

\begin{tabular}{|c|c|}
\hline Stage & Content \\
\hline \multicolumn{2}{|l|}{ Introduction } \\
\hline & $\begin{array}{l}\text { Clarification of the focus group procedure, written informed consent, and warming- } \\
\text { up questions to introduce participants. }\end{array}$ \\
\hline \multicolumn{2}{|l|}{ Drivers and barriers of fish consumption } \\
\hline & Main factors affecting fish and seafood consumption positively and negatively. \\
\hline \multicolumn{2}{|l|}{$\begin{array}{l}\text { Drivers and barriers of fish burger } \\
\text { consumption }\end{array}$} \\
\hline & Reasons to (not) purchase and consume generic fish burgers. \\
\hline & Influence of product attributes on participants' acceptance of generic fish burgers. \\
\hline \multicolumn{2}{|l|}{ Acceptance of functional fish burgers } \\
\hline & $\begin{array}{l}\text { Attitudes toward fish burgers with added selected functional ingredients delivering } \\
\text { specific health benefits. } \\
\text { Motivational factors of preferred functional ingredients. }\end{array}$ \\
\hline \multicolumn{2}{|l|}{$\begin{array}{l}\text { Consumer perception of selected health } \\
\text { and nutritional claims }\end{array}$} \\
\hline & $\begin{array}{l}\text { Meaning ascribed to various claims available under Regulation } 1924 / 2006 \text { and } \\
\text { preference for the claim that they would like to find on the product. }\end{array}$ \\
\hline
\end{tabular}

192

The discussion lasted approximately two hours. Each focus group took place in a

194 conference room and was video recorded with the permission of the participants. The 


\section{INSIGHTS FOR NEW FUNCTIONAL FISH PRODUCTS}

195 discussion was conducted by a moderator and an assistant who started each focus group with

196 a brief overview of the study and with warm-up questions giving participants the opportunity

197 to ask any questions before starting to collect information. Discussion on the identified

198 research topics was triggered by the moderator with open-ended questions while the assistant

199 observed participants taking notes.

\section{Data Analysis}

The videotapes and verbatim transcripts were coded and analysed based on a thematic analysis, a method for identifying, analysing and reporting patterns (themes) within text data (Braun \& Clarke, 2006).

Qualitative data was analysed in three stages. In stage one, the voice recording of

205 focus group discussions were transcribed verbatim into a word document. In stage two, the transcriptions were analysed using thematic analysis to obtain insights about the content of discussion, to identify different themes contained in data, and to create a structured coding system. To minimize subjectivity bias, transcripts were independently analysed by two coders who discussed differences in coding until they agreed on a collection of 54 codes that were

210 combined into broader themes. Accordingly, a total of 29 themes were elaborated: 8 themes

211 about drivers and barriers of fish consumption, 7 themes about drivers and barriers of conventional fish burger consumption, 10 themes about the acceptance of functional fish burgers, and 4 themes about consumer perceptions of health and nutritional claims. In stage

214 three, transcribed data were imported into NVIVO 10 to further reduce researchers'

215 subjectivity in analysing qualitative data. Results of the four focus group discussions are

216 presented by order of themes included in the research protocol and using participants' quotes.

217 Furthermore, the main results are discussed at aggregate level but when substantial

218 differences among participants were found, they are marked appropriately. 
INSIGHTS FOR NEW FUNCTIONAL FISH PRODUCTS

Table 3. Themes of focus group discussions.

\begin{tabular}{|c|c|c|c|}
\hline $\begin{array}{l}\text { Drivers and barriers of } \\
\text { fish consumption }\end{array}$ & $\begin{array}{l}\text { Drivers and barriers of fish } \\
\text { burger consumption }\end{array}$ & Acceptance of functional fish burgers & $\begin{array}{c}\text { Consumer perception of } \\
\text { health and nutritional claims }\end{array}$ \\
\hline 1. Health beliefs & 9. Convenience & 16. Healthy food & $\begin{array}{l}\text { 26. Nutritional claim with the } \\
\text { indication of higher } \\
\text { content }\end{array}$ \\
\hline 2. Nutritional knowledge & 10. Appealing to children & 17. Concern about taste & $\begin{array}{l}\text { 27. Function claim vs. } \\
\text { reduction of disease risk } \\
\text { claim }\end{array}$ \\
\hline 3. Sensory liking of fish & $\begin{array}{l}\text { 11. Curiosity and desire to } \\
\text { vary }\end{array}$ & 18. Truthfulness of functional foods & $\begin{array}{l}\text { 28. Combination of short } \\
\text { nutrition claims and full } \\
\text { health claims }\end{array}$ \\
\hline 4. Price perception & $\begin{array}{l}\text { 12. Concerns about the } \\
\text { taste and texture of } \\
\text { fish burgers }\end{array}$ & $\begin{array}{l}\text { 19. Carrier and ingredient combinations: } \\
\text { natural vs. artificial }\end{array}$ & $\begin{array}{l}\text { 29. Visual aids and } \\
\text { trustworthiness of claims } \\
\text { on functional fish burgers }\end{array}$ \\
\hline 5. Lack of convenience & $\begin{array}{l}\text { 13. Concerns about quality } \\
\text { and safety of fish } \\
\text { burgers }\end{array}$ & 20. Familiarity with omega 3 & \\
\hline $\begin{array}{l}\text { 6. Concerns about fish } \\
\text { consumption process }\end{array}$ & $\begin{array}{l}\text { 14. Impact of branding } \\
\text { and labeling }\end{array}$ & $\begin{array}{l}\text { 21. Usefulness of omega } 3 \text { for } \\
\text { maintaining good health and well- } \\
\text { being }\end{array}$ & \\
\hline 7. Lack of fish availability & $\begin{array}{l}\text { 15. Influence of product } \\
\text { attributes }\end{array}$ & 22. Prevention vs. aurative effects & \\
\hline \multirow{2}{*}{$\begin{array}{l}\text { 8. Lack of trust in } \\
\text { information provided } \\
\text { by fish sellers }\end{array}$} & & 23. Knowledge of omega 3 daily intake & \\
\hline & & $\begin{array}{l}\text { 24. Medium-low-risk perception of } \\
\text { cardiovascular diseases and } \\
\text { convenience of functional fish } \\
\text { burgers } \\
\text { 25. High-risk perception of } \\
\text { cardiovascular diseases }\end{array}$ & \\
\hline
\end{tabular}

\section{Results and Discussion}

\section{Drivers and Barriers of Fish Consumption}

Consistent with the literature (Brunsø et al., 2009; Burger \& Gochfeld, 2009; Pieniak,

225 Verbeke \& Scholderer, 2010; Verbeke et al., 2005), all respondents agreed that fish and

seafood are healthy foods and their consumption is useful for a balanced diet. There was also

than meat. The perception of fish as healthy food was mainly explained by general comments 


\section{INSIGHTS FOR NEW FUNCTIONAL FISH PRODUCTS}

I eat fish because it is good for my health and rich in nutrients.

Fish contains vitamins and proteins which are essential for a balanced diet.

Fish is more easily digestible than meat and good for children's growth ... and unlike meat, hormones are not used in the production of fish.

However, in line with past studies (Brunsø et al., 2009; Carlucci et al., 2015; Pieniak et al., 2007; Pieniak, Verbeke \& Scholderer, 2010), only a few participants (mainly older men and women) really knew about specific nutrients contained in fish and specific health benefits provided by fish consumption. Actually, participants' previous perceived health beliefs regarding fish were reinforced by the wrong credence linked to the popular myth that fish consumption increases intelligence and was not supported by their appropriate knowledge on specific nutrients beneficial to human nutrition (theme 2).

Fish contains proteins ... Calcium is a protein.

Fish is good for health ... I do not know why, just by word of mouth.

Fish is brain food.

The head of the fish is the part of the fish which contains more vitamins.

In line with the literature (Birch \& Lawley, 2012; Carlucci et al., 2015; Brunsø et al., 2009; Neale et al., 2012), the majority of respondents declared that they were attracted by the sensory properties of fish because they like the taste, the texture and the aroma of fish and, in general, enjoy eating fish (theme 3).

\section{I don't look at nutrients, taste is important for me...I eat fish because I like} the taste.

Fish is one of the few foods that you can eat without dressing, it tastes good plain.

I love fish for its good taste and its aroma of the sea. 


\section{INSIGHTS FOR NEW FUNCTIONAL FISH PRODUCTS}

reported in other studies (Brunsø et al., 2009; Carlucci et al., 2015; Neale et al., 2012;

Verbeke \& Vackier, 2005). Participants stated that fish cannot be eaten every day because is a more expensive meal option than meat and seems to be a food product that is consumed more by wealthier people (theme 4).

Fish is far more expensive than meat.

Most participants also agreed that fish consumption, particularly fresh fish, is affected negatively by the time and effort required for its preparation (Birch \& Lawley, 2012; Bruns $\varnothing$ et al., 2009; Carlucci et al., 2015; Neale et al., 2012; Olsen et al., 2007). Time is also affected by the short shelf-life of fish because consumers must cook fish straight away if they want appreciate the organoleptic characteristics of this product (theme 5).

I would like to just eat fresh fish but I don't have time...

The preparation of dishes based on fresh fish involve time and care.

Fresh fish is highly perishable...you have to eat it at once and cannot keep

the lack of knowledge and skills in selecting and preparing fish (Birch \& Lawley, 2012;

Carlucci et al., 2015; Neale et al., 2012; Pieniak et al., 2007). Specifically, younger

participants declared that they did not feel confident in assessing freshness of fish and cooking it at home (theme 6). can prepare without difficulty is sole. 
INSIGHTS FOR NEW FUNCTIONAL FISH PRODUCTS

It's hard to know when fish is really fresh, I can't tell.

Several participants also indicated that fresh fish is not always available in the marketplace (Rortveit \& Olsen, 2007; Rortveit \& Olsen, 2009) (theme 7). They were also concerned about the origin of fish and this was exacerbated by the lack of trust in information provided by fishmongers (Claret et al, 2012; Pieniak et al., 2017) (theme 8).

Fresh fish isn't always available.

When you buy fresh fish you never know what will be available...it

\section{Drivers and Barriers of Fish Burger Consumption} depends on the catch.

\section{Where fish comes from is fundamental ... I don't trust what the fishmonger} says. their convenience. They expressed the desire to save time and effort in the preparation of fish meals" (theme 9). quick and easy meal option. fish product because they are appealing for children who often dislike the taste and smell of fresh fish as well as the presence of bones (Birch \& Lawley, 2012; Verbeke \& Vackier,

317 2005). They claimed to be continuously engaged in searching for new processed fish products

318 that their children could like (theme 10). 


\section{INSIGHTS FOR NEW FUNCTIONAL FISH PRODUCTS}

I buy it so we can give the children a little fish in alternative to what we already eat.

My children hate the smell of fish and its bones...this could be a way to convince them to eat fish.

Many respondents emphasized that they routinely like to vary the choice of food products available on the market and are attracted by new food products (Kaushik \& Rahman, 2014; Olsen et al., 2016). They agreed that fish burgers are a particular fish product that is different from others and could be eaten to break the monotony of this category of food products (theme 11).

Fish is a different product you could buy it now and again to ring the changes.

I'd try it out of curiosity. However, a few respondents (older and more expert in selecting and preparing fish) showed a negative attitude towards fish burgers. They stated that they never would buy fish burgers because they perceived this product as being unappealing in terms of taste and texture. They also emphasized the difficulty of breaking their ingrained habits of buying and consuming fresh fish (Siegrist, Hartmann \& Keller, 2013; Carlucci et al., 2015) because of the unique reward that they get when eating this delicious and healthy product (theme 12).

I wouldn't buy it...it looks weird...it's not fish to me.

I'm used to eating only fresh fish...I wouldn't buy anything similar. I don't think it would have neither the taste nor the nutritional properties of fish.

Concern for this product was also expressed by participants with positive attitudes. They were concerned about the quality and safety attributes of fish burgers. These are credence attributes and, considering that fish burgers are prepared with the minced flesh of fish, 


\section{INSIGHTS FOR NEW FUNCTIONAL FISH PRODUCTS}

participants showed a lack of trust towards the production process because they feared that it could be made with waste and by-products of the fish industry (theme 13). These results corroborate previous findings highlighting a on consumers' negative perception over fish processing (Altintzoglou et al.,2010; Debucquet, Cornet, Adam, \& Cardinal, 2012).

I would be worried that they are made out of fish by products...may be polluted fish or fish that has gone off.

They might be made out of by-products like meatballs...I'd be scared... The thing is, you can't see what you are actually eating.

They also discussed how to overcome their concerns. They stated that branding and labelling could play an important role to assure consumers in terms of quality and safety (Verbeke, Vermeir \& Brunsø, 2007) especially if fish burgers are produced by big food companies with a long-standing brand and trust relationship with consumers in the market place (theme 14).

I'd like to see labelling with the characteristics of the fish...I'd like the same information on whole fish. It is the only way to stop prejudice.

Brand is trust...brand is synonymous with quality as it guarantees that it hasn't been frozen and defrosted.

I'd like to see the brand of a big food company then I would feel assured regarding quality.

Concerning the most important attributes affecting the quality of fish burgers (theme 15), almost all respondents agreed to be extremely interested in the species of fish used and they also expressed a preference for salmon and cod with the latter cited particularly for children. The storage method was the second most relevant attribute considered by participants who distinguished between chilled and frozen fish burgers. Most participants claimed to prefer frozen fish burgers for their longer shelf-life and ready availability as "emergency meals" 


\section{INSIGHTS FOR NEW FUNCTIONAL FISH PRODUCTS}

377 (Birch \& Lawley, 2012; Claret et al., 2012). Country of origin was another important attribute

378

379

380

381

382

383

384

385

386

387

388

389

390

391

392

393

394

395

396

397

398

401

402

403

404

405 valued by many participants who also agreed to prefer domestic fish for its superior quality and safety compared to imported fish (especially fish from developing countries) (Carlucci et al., 2015; Claret et al., 2012). Finally, most respondents highlighted that price is a key factor affecting the choice of purchasing fish burgers and they agreed to be willing to purchase fish burgers only if price is lower than that of fresh fish.

I look at the type of fish...I'd like it made from salmon.

.....thinking of my children I'd rather the burgers were made of cod.

Obviously the burgers would need to be frozen ... otherwise you'd have to eat them asap and that would lessen convenience... the flavour of fish, unlike meat, changes after a day.

I'd look at the origin of the fish carefully ... I would obviously prefer Italian or Mediterranean fish...I would certainly not buy fish from China as I wouldn't trust it.

Price is fundamental...if the price was the same as fresh fish I wouldn't buy it.

\section{Acceptance of Functional Fish Burgers}

Most respondents showed a positive attitude towards functional fish burgers mainly because they were perceived as being healthier than generic fish burgers. In particular, older women from Rome and Bologna agreed that the addition of functional ingredients providing health benefits would be a good idea to enhance the quality of this product and differentiate it from conventional fish burgers (theme 16).

I like the idea that they contain some healthy ingredients....that's a plus with respect to plain fish burgers.

They're different from the classic fish burgers you find in fast food outlets...they're heathier... kill two birds with one stone. 


\section{INSIGHTS FOR NEW FUNCTIONAL FISH PRODUCTS}

406

407

408

409

410

411

412

413

414

415

416

417

418

419

420

421

422

423

424

425

426

427

428

429

430

431

432

433

However, despite the fact that participants liked the idea of functional fish burgers, some of them (middle-aged men from Rome and Bologna) expressed concerns over the taste that may result altered and/or unnatural after the addition of a particular functional ingredient (theme 17).

Adding substances could change the flavour of the fish.

If you add substances the burger might not have a natural taste.

Furthermore, some participants (women below 40) were sceptical about this enrichment because of distrust regarding the utility of functional foods (theme 18). In line with Lalor et al. (2011), the sceptics showed a holistic approach to health and believed that just one product is not enough to improve an individual's health which is instead affected positively by a varied diet. These participants also stated that, instead of consuming functional foods, a Mediterranean diet would be sufficient to maintain good health and wellbeing.

I don't believe in foods that are enriched with other ingredients...often these foods don't have the same effect as natural foods.

Eating an enriched food is not going to improve your health... we have our Mediterranean diet that gives us all these nutrients...we don't need to add anything.

As regards the addition of functional ingredients, in line with other studies (Cox, Evans \& Lease, 2011; Krutulyte et al., 2011; Lampila et al., 2009), almost all participants agreed that functional fish burgers should be produced by enriching the content of an ingredient which is already naturally contained in fish (theme 19). 
INSIGHTS FOR NEW FUNCTIONAL FISH PRODUCTS

I'd like the burgers enriched with ingredients that are already present in fish...I think it's absurd to add fibre...

The most mentioned functional ingredients that would be preferred for enriching fish burgers were Omega-3, Phosphorus, Iron and Calcium. When participants were asked to choose the most preferred nutrient with which to fortify the product, almost all of them agreed on Omega-3. They motivated this choice saying that they were familiar with this nutrient owing to the fact that they heard about it from their family doctors, media and several marketed food products that are already fortified with Omega-3, citing milk and yogurt (theme 20).

There are already lots of foods containing Omega-3...there's milk with Omega-3, yogurt with Omega-3.

I've heard the family doctor talk about Omega-3.

They talk about it all the time in TV much more than in the past...chefs, nutritionist talk about it...

Furthermore, they motivated this choice saying that fish contains this nutrient naturally contrarily to other functional foods like milk or yogurt to which it is conventionally added.

Certainly if I have the choice I would prefer to eat a fish burger enriched with Omega-3 rather than milk or yogurt.

However, the omega-3 fatty acid concentration is very low in cod which is one of the most preferred species of fish for consumption and this denotes consumers`lack of nutritional knowledge.

.Furthermore, they also admitted to have a limited knowledge of the specific health benefits of Omega-3 but they generally knew that Omega-3 fatty acids are very important for maintaining good health and well-being (theme 21). However, some participants knew that Omega-3 could prevent cardiovascular diseases but that did not have any medicinal effects confirming findings by Krutulyte et al. (2008) (theme 22). 


\section{INSIGHTS FOR NEW FUNCTIONAL FISH PRODUCTS}

462

463

464

465

466

467

468

469

470

471

472

473

474

475

476

477

478

479

480

481

482

483

484

485

486

487
I don't know precisely what Omega-3 are...I think they can generally guarantee better health and can help prevent cardiovascular diseases but certainly not cure them ...

...they help prevent health problems but not cure them.

The discussion on Omega-3 also highlighted that an increased intake of fatty fish does not seem to have any effects on consumers. Some participants stated that this pattern could be explained by the fact that consumers do not know the quantity of fish that would provide an optimal intake of Omega-3 and thus they are uncertain about whether they consume enough Omega-3 (theme 23). As a result, these participants argued that the evaluation of the right intake of Omega-3 could be facilitated by functional foods displaying labels, where recommended daily intakes are explicitly indicated..

I am predisposed to high blood pressure and I have given up meat and increased my fish intake... I have had no positive effects...maybe because I don't know how much fish I should eat to get the right amount of Omega-3 ... I would like to see the quantity of Omega-3 and recommended intake on burger labels.

As regards the link between the consumption of Omega-3 and perceived risk of getting cardiovascular diseases, most participants claimed that they thought that they were exposed to a medium-low risk and thus they were not afraid of developing cardiovascular disease because their diet and lifestyles were sufficiently healthy. These participants also admitted that maintaining a balanced diet is often difficult primarily because of lack of time due to busy lifestyles and thus fish burgers enriched with Omega-3 could be a good surrogate of fatty fish like salmon (theme 24).

488 


\section{INSIGHTS FOR NEW FUNCTIONAL FISH PRODUCTS}

I think I have a low risk of contracting cardiovascular disease....or the same risk as others my age...I do sport and watch what I eat...of course I can't always eat salmon that is rich in Omega-3...I could eat an Omega-3 enriched burger.

However, few participants also declared that they felt they were at high risk of cardiovascular diseases and most of them construed their risks as exogenous to their behaviour, i.e. as simple consequence of aging and/or genetic predisposition (high levels of cholesterol and hypertension). These participants strongly chose Omega-3 as their preferred enrichment functional ingredient and thus their motivation to protect themselves against this risk (theme 25).

As far as I am concerned, the consumption of these fish burgers can help me because I am prone to high levels of cholesterol and therefore I run a high risk of developing cardiovascular diseases.

\section{Consumer Perception of Health and Nutritional Claims}

Given that Omega-3 was the most preferred functional ingredient to be added to fish burgers, different nutritional and health claims permitted by EU Regulation 1924/2006 and available on the EFSA website for Omega-3 were presented to the participants. In particular, nine front labels were selected with five front labels being nutritional claims and four substantiated health claims. For the five nutritional claims, the noun Omega-3 was preceded by qualifiers which indicated progressive levels of the functional ingredient concentration: “source of Omega-3”, “contains Omega-3”, “with Omega-3”, “high in Omega-3” and "rich in Omega-3". As regards health claims, the following two were selected from those approved by EFSA in May 2012 (Reg. No 432/2012) and available on the EFSA website: "Omega-3 contributes to the maintenance of normal blood cholesterol levels" and "Omega-3 reduces risk of coronary heart disease". Both claims were presented to participants with and 


\section{INSIGHTS FOR NEW FUNCTIONAL FISH PRODUCTS}

517 without the following information: "This health claim has been approved by EFSA after substantiated scientific evidence".

In line with literature (Mariotti et al., 2010), most participants did not clearly

distinguish between different types of nutritional claims. However, results are interesting

because the use of qualifiers influenced participants' attitudes of different nutritional claims.

Specifically, when Omega-3 was preceded by the qualifiers "source of", "contains" and

"with", participants appeared to perceive the communication of the functional ingredient as

because especially "contains" gives the idea that something was added to the product. On the other hand, when Omega-3 was preceded by the qualifiers "high" and "rich", many participants questioned their meaning in terms of quantity because they wanted to know the right amount of Omega-3 that they had to take daily. Furthermore, participants below the age of 40 preferred the term "rich" for its simplicity and its more positive impact than "high" on information processing. However, despite these remarks the use of the qualifiers "high" and "rich" were effectively perceived as communicating a higher content of Omega-3 in comparison to the qualifiers "source of", "contains" and "with". Thus, these results seem to indicate that the strength of qualifiers can play a very important role in the communication of nutritional claims. This aspect can be well accepted when the added functional ingredient is already contained naturally in the food products as in the case of fish burgers. is higher than what is available naturally... general mention of health benefits (i.e. maintenance of normal blood cholesterol levels) 


\section{INSIGHTS FOR NEW FUNCTIONAL FISH PRODUCTS}

543 incomparison to claims conveying specific information concerning risk reduction of getting

544 coronary heart diseases (theme 27). These results are also confirmed by Kapsak et al. (2008).

545

546

547

548

549

550

551

552

553

554

555

556

557

558

559

560

561

562

563

564

565

566

567

568

569

570

"Reduces cholesterol" is a simple and direct label.

In the end I am buying fish burgers... for me reference to cholesterol is more than enough.

I don't like "Reduces risk of cardiovascular disease" at all...horrible and inadequate... I am not buying pills... sounds like something I'd buy at the chemists .

Moreover, consistent with the literature (Williams, 2005), some participants declared that they preferred a combination of short nutritional claims on the front of the package and full health claims on the back (theme 28).

On the front label I prefer "rich in Omega-3" because it's simple, short and direct, has an impact... on the back you could say that "Omega-3 reduces cholesterol".

Finally, also in this study some participants expressed lack of trust in health and nutritional claims (Kearney, 2010; Grunert, 2010) and they agreed that trust would be higher if the strength of the claims was communicated using visual aids rather than without (Hooker \& Teratanavat, 2008; Kapsak et al., 2008) (theme 29).

It is not reading Omega-3 on the label that is going to make me see that it is something that is good for my health... I don't believe this much...

It was also interesting to observe that while the majority of participants felt that claims displaying "This health claim has been approved by EFSA after substantiated scientific 


\section{INSIGHTS FOR NEW FUNCTIONAL FISH PRODUCTS}

evidence" generate a sense of trust towards the properties of the product. , few participants had the opposite feeling.

\section{For a new product with a claim I don't know, a reference to the European} Safety Authority would be an added guarantee.

However, a few participants showed a lack of trust towards EFSA especially males who stated being sceptical on reinforcing the strength of scientific evidence with a sentence emphasizing EFSA approval. Some of these participants perceived this type of reinforcement more suitable for a medicinal product approved by a board of medical doctors.

\section{Conclusions}

In this study, four focus groups were conducted to explore consumers' acceptance of new functional fish burgers and thus findings are not conclusive, and follow-up studies based on larger and representative samples should be conducted to validate consumers' acceptance of these new products. Furthermore, this study provides insights regarding the development of new functional fish products, consumer understanding of nutrition and health claims and for future research, but the study also confirms findings of past studies thanks to the detailed semi-structured focus group research protocol.

The study confirms that, in general, fish is widely perceived by consumers as a healthy and tasty food but barriers such as perceived high prices, lack of convenience, lack of knowledge about fish and cooking skills and lack of fish availability limit its consumption. However, in relation to fish burgers the study revealed that most participants showed a positive attitude towards fish burgers because of convenience, the desire of varying fish consumption and the presence of children. Frozen fish burgers were preferred over the alternative fresh product because of convenience and ready availability. These findings as 


\section{INSIGHTS FOR NEW FUNCTIONAL FISH PRODUCTS}

597 well as being interesting to marketers in terms of developing targeted marketing campaigns on aspects mentioned above, they also inform food processors about attributes to consider for product development. Product attributes such as species of fish, type of functional ingredient,

600 freshness and safety, country of origin, price and brands were all considered important by

601 participants. Positive consumer acceptance of functional fish burgers emerging from this

602 qualitative study is also interesting because it should invite food processors and policy makers to think about market opportunities to reduce the post-harvest losses of by-products

604 of the fish industry (FAO, 2016). It is well-known that the fish industry generates large

605 quantities of by-products that contain proteins and lipids which could be a source of nutrients

606 for humans and therefore used in the development of functional fish products designed for

607 human consumption (Tahergorabi, Matak \& Jaczynski, 2015).

608 Consumer acceptance of fish burgers can be facilitated by the use of appropriate

609 extrinsic cues conveyed by labels. Labelling is important because consumers seem to be

610 extremely interested in being informed about the species and geographical origin of fish used

611 for making fish burgers. In particular, participants were attracted by fish burgers which could

612 be made using salmon and cod preferably produced domestically because considered of 613 superior quality and safer in comparison to imported fish. The idea of producing functional

614 fish burgers seems to be well appreciated by most participants if the functional ingredient is

615 already naturally present in the fish. Specifically, the most preferred functional ingredient for 616 enriching fish burgers was Omega-3 because it is already naturally contained in fish contrary

617 to other functional foods like milk or yogurt. Furthermore, although consumer knowledge of

618 Omega-3 health effects is limited, participants' familiarity with this functional ingredient

619 considerably affects the acceptance of functional fish burgers because it is believed to

620 improve human health and well-being preventing cardiovascular diseases. However, some

621 participants were concerned about the Omega-3 enrichment effects on the taste of fish 


\section{INSIGHTS FOR NEW FUNCTIONAL FISH PRODUCTS}

burgers and were uncertain whether they consumed enough Omega-3. Thus food companies should clearly indicate the recommended daily intake of functional ingredients. Regarding risk perception, the food industry could take into account that participants seemed to be more willing to consume fish burgers fortified with Omega-3 in order to improve their well-being and decrease their risk of getting cardiovascular diseases rather than achieving therapeutic effects.

The relatively low price of fish burgers in comparison to more conventional fish products was another attribute positively stimulating consumers' acceptance. Brands can transmit and ensure product quality to consumers, but food companies with a long-standing brand seem to be more trusted than companies that do not have this long market relationship with consumers. The use of nutrition and health claims could add value to brands but their use should be evaluated carefully because participants found it challenging to interpret information conveyed by qualifiers.

To qualify the claim of a food products means limiting the property or content of a certain attribute using words like "with" or "contain" or "high" and so on. These words are qualifiers that differentiate a claim from concepts such as "all" or "always". Results indicate that when nutritional claims use strong qualifiers such as "high" and "rich" in Omega-3 these are better received than weak qualifiers such as "source of", "contains" and "with" Omega3.In other words one might think that these qualifiers are sort of quantifiers because they give the idea that "high" is more than "contain" and "rich" is more than "high". However, to what extent qualifiers quantify a particular product attribute is difficult to say because they act like an ordinal scale where the magnitude between two points is not exactly quantifiable.

Concerning health claims, participants appeared to prefer those conveying general health benefits (e.g. cholesterol reduction) in comparison to claims containing too much specific information on the risk reduction of cardiovascular diseases. Moreover, many 


\section{INSIGHTS FOR NEW FUNCTIONAL FISH PRODUCTS}

647 participants preferred a combination of a short nutritional claim on the front of the package

648 and a full health claim on the back. Trust towards health claims seems generally to be higher

649 when the strength of the claims is substantiated by EFSA and is communicated using visual

650 aids rather than words. Thus, while these results confirm that the strength of qualifiers, the

651 structure of the language and visual aids play an important role in the communication of

652 nutritional and health claims, European legislators finds it difficult to provide sufficient

653 guidance on how these different aspects can be used to support the communication of

654 scientific substantiated health claims to consumers (Richardson, 2012). Probably this

655 difficulty lies in the complexity of health claims because from an economic point of view

656 they are information remedies used by the legislator to tackle problems of market failure,

657 while from a linguistic point of view they are complex discursive acts involving both

658 semantic and pragmatic dimensions (Jones, 2014a). Information conveyed by health claims is

659 further complicated by the that fact that the communication of claims usually involves modes

660 other than language such as images, font, layout, colour and the texture of packaging material

661 (Jones, 2014b), which requires looking at claims from an information design perspective.

662 So far there is a surprising lack of multidisciplinary research aimed at evaluating how these dimensions interact and influence consumers when they process information conveyed

664 by health claims. The work of the legislator should be supported definitively and urgently by 665 interdisciplinary research involving disciplines such as economics, food science, linguistics, 666 nutrition and typography. This is because qualified health claims are relevant not only to the 667 diversity of European countries but also to other countries because they demonstrate language 668 and communication strategies that may or may not help consumers make informed decisions 669 (Berhaupt-Glickstein et al., 2014). 


\section{INSIGHTS FOR NEW FUNCTIONAL FISH PRODUCTS}

Finally, the findings of this study should be supported by studies where sensorial

672

673

674

675

676

677

678

679

680

681

682

683

684

685

686

687

688

689

690

691

692

693

694

695

analysis is taken into account. A recent study conducted by Branciari et al. (2017) highlights the importance of this aspect when investigating the nutritional profile of fish burgers via sensorial analysis. In their study, they found that that the species used to make fish burgers such as carp, goldfish, perch, and tench influence the overall liking and taste of these products and as a consequence consumers acceptance and their purchasing intention. However, the idea of developing these new functional fish products should be supported by research which simultaneously evaluates both intrinsic (sensory) and extrinsic factors (brand, price, health claims etc.) of new functional food. This type of approach has been growing fast during the last ten years and several researchers have been employing so called alternative descriptive methods or rapid methods to obtain more complete and realistic information about consumer behaviour in real life buying and eating situations (Asioli et al., 2017). New methodologies like projective mapping, check-all-that-apply and flash profiling are less time-consuming than classic descriptive methods (conjoint hedonic methods and classic hedonic testing), more flexible, and can be performed by both trained and non-trained assessors (Varela \& Ares, 2012). By properly incorporating consumers`voices in research and development activities can reduce the high rate of failure of new functional food products, but more effort is required on behalf of researchers and the food industry in terms of investment and a more open minded approach to tackle the interdisciplinary challenge of putting together a large number of disciplines such as biology, consumer science, economics, food science, linguistics, marketing, physiology, psychology, sociology, sensory, and typography. 
INSIGHTS FOR NEW FUNCTIONAL FISH PRODUCTS

696

697

698

699

700

701

702

703

704

705

706

707

708

709

710

711

712

713

714

715

716

717

718

719

\section{References}

Asioli, D., Varela, P, Hersleth, M., Lengard Almli, V., Veflen Olsen, N. and Næs. T.(2017). A discussion of recent methodologies for combining sensory and extrinsic product properties in consumer studies. Food Qual and Prefe, 56: 266-73

Altintzoglou, T., Einarsdottir, G., Valsdottir, T., Schelvis, R., Skå ra, T., \& Luten, J. 2010. A voice-of-consumer approach in development of new seafood product concepts. J. Aquat. Food Prod. T. 19(2): 130-145.

Altintzoglou, T., Sveinsdottir, K., Einarsdottir, G., Schelvis, R., \& Luten, J. B. 2012. Evaluation of Seafood Product Concepts by Young Adults and Families with Young Children from Denmark, Norway, and Iceland. J. Aquat. Food Prod. T. 21(5): 418-432.

Altintzoglou, T., \& Heide, M. 2016. Fish Quality and Consumers: How Do Consumers' Knowledge About and Involvement in Fish Quality Define Factors That Influence Fish Buying Behavior J. Aquat. Food Prod. T. 25(6): 885-894.

Annunziata, A., \& Vecchio, R. 2011. Functional foods development in the European market: A consumer perspective. J. Funct. Foods. 3(3): 223-228.

Ares, G., Giménez, A., \& Gámbaro, A. 2008. Influence of nutritional knowledge on perceived healthiness and willingness to try functional foods. Appetite, 51:663-668.

Bech-Larsen, T., \& Grunert, K. G. 2003. The perceived healthiness of functional foods: A conjoint study of Danish, Finnish and American consumers' perception of functional foods. Appetite. 40: 9-14.

Berhaupt-Glickstein, A., Nucci, M. N., Hooker, N. H., Hallman, W. K. 2014. The evolution of language complexity in qualified health claims. Food Policy. 47: 62-70.

Birch, D., \& Lawley, M. 2012. Buying seafood: understanding barriers to purchase across consumption segments. Food Qual. Prefer. 26(1): 12-21. 


\section{INSIGHTS FOR NEW FUNCTIONAL FISH PRODUCTS}

720 Birch, D., \& Lawley, M. 2014. The role of habit, childhood consumption, familiarity and attitudes across seafood consumption segments in Australia. J. Food Prod. Market. 20(1): 98-113.

Bleiel, J. 2010. Functional foods from the perspective of the consumer: How to make it a success? Int. Dairy J. 20(4): 303-306.

Bochi, V. C., Weber, J., Ribeiro, C. P., Victório, A. D. M., \& Emanuelli, T. 2008. Fishburgers with silver catfish (Rhamdia quelen) filleting residue. Bioresource Technol. 99(18): 8844-8849.

Branciari, R., Ranucci, D., Urbani, E., Valiani, A., Trabalza-Marinucci, M., Bosco, A. D., \& Franceschini, R. 2016. Freshwater fish burgers made from four different fish species as a valuable strategy appreciated by consumers for introducing EPA and DHA into a human diet. J. Aquat. Food Prod. T. (In Press).

Braun, V., \& Clarke, V. 2006. Using thematic analysis in psychology. Qual. Res. Psychol. 3: $77-101$.

Brunsø, K., Verbeke, W., Olsen, S. O., \& Jeppesen, L. F. 2009. Motives, barriers and quality evaluation in fish consumption situations. Exploring and comparing heavy and light users in Spain and Belgium. Brit. Food J. 111(7): 699-716.

Burger, J., \& Gochfeld, M. 2009. Perceptions of the risks and benefits of fish consumption: Individual choices to reduce risk and increase health benefits. Environmental research, 109(3), 343-349.

Carlucci, D., Nocella, G., De Devitiis, B., Viscecchia, R., Bimbo, F., \& Nardone, G. 2015. Consumer purchasing behaviour towards fish and seafood products. Patterns and insights from a sample of international studies. Appetite. 84: 212-227.

Claret, A., Guerrero, L., Aguirre, E., Rincón, L., Hernández, M. D., Martínez, I., ... \& Rodríguez-Rodríguez, C. (2012). Consumer preferences for sea fish using conjoint 


\section{INSIGHTS FOR NEW FUNCTIONAL FISH PRODUCTS}

analysis: Exploratory study of the importance of country of origin, obtaining method, storage conditions and purchasing price. Food Quality and Preference, 26(2), 259-266.

Cox, D. N., Evans, G., \& Lease, H. J. 2011. The influence of product attributes, consumer attitudes and characteristics on the acceptance of: (1) Novel bread and milk, and dietary supplements and (2) fish and novel meats as dietary vehicles of long chain omega 3 fatty acids. Food Qual. Prefer. 22: 205-212.

Cox, D. N., Koster, A., \& Russell, C. G. 2004. Predicting intentions to consume functional foods and supplements to offset memory loss using an adaptation of protection motivation theory. Appetite. 33: 55-64.

Debucquet, J. C., Cornet, J., Adam, I., \& Cardinal, M. 2012. Perception of oyster-based products by French consumers. The effect of processing and role of social representations. Appetite. 59(3): 844-852.

de Quadros, D. A., de Oliveira Rocha, I. F., Ferreira, S. M. R., \& Bolini, H. M. A. 2015. Lowsodium fish burgers: Sensory profile and drivers of liking. LWT- Food Sci. Technol. 63(1): $236-242$

.Di Monaco, R., Cavella, S., Masi, P., Sevi, A., Caroprese, M., Marzano, A., ... \& Del Nobile, M. A. 2009. Blue fish burgers: nutritional characterisation and sensory optimisation. Int. J. Food Sci. Tech. 44(8): 1634-1641.

FAO/WHO 2011. Report of the joint FAO/WHO expert consultation on the risks and benefits of fish consumption. Rome, Geneva: Food and Agriculture Organization of the United Nations, World Health Organization.

FAO (2016). Fisheries and Aquaculture topics. Utilization and trade. Topics Fact Sheets. In: FAO Fisheries and Aquaculture Department. Available online at: http://www.fao.org/fishery/utilization_trade/en 


\section{INSIGHTS FOR NEW FUNCTIONAL FISH PRODUCTS}

769 Gilbert, L. 2000. The functional food trend: What is next and what Americans think about eggs.

770

771

772

773

774

775

776

777

778

779

780

781

782

783

784

785

786

787

788

789

790

791

792 J. Am. Coll. Nutr. 19: 507S-512S.

Granato, D., Branco, G. F., Cruz, G., Faria, J. F., Shah, N. P. 2010. Probiotic Dairy Products as Functional Foods. Compr. Rev. Food Sci. F. 9: 455-470.

Griffiths J.C., Abernethy D.R., Schuber S. and Williams R.L. 2009. Functional food ingredient quality: Opportunities to improve public health by compendial standardization. J. Funct. Foods. 1: 128-130.

Grunert, K. G. 2010. European consumers' acceptance of functional foods. Ann. Ny. Acad. Sci. 1190:166-73.

Haq, M., Dutta, P. L., Sultana, N., \& Rahman, M. A. 2013. Production and quality assessment of fish burger from the grass carp, Ctenopharyngodon idella (Cuvier and Valenciennes, 1844). J.F. 1(1), 42-47.

Hailu, G., Boecker, A., Henson, S., \& Cranfield, J. 2009. Consumer valuation of functional foods and nutraceuticals in Canada. A conjoint study using probiotics. Appetite, 52: $257-265$.

Hooker, N. H., \& Teratanavat, R. 2008. Dissecting qualified health claims: evidence from experimental studies. Crit. Rev. Food Sci. Nutr. 48: 160-176.

Jones, R. (2014a). Unwriting food labels: Discursive challenges in the regulation of package claims. Journal of Business and Technical Communication, 28 (4): 1-32.

Jones, R. (2014b) The multimodal dimension of claims in food packaging. Multimodal Communication, 3 (1): 1-10.

Kapsak, W. R., Schmidt, D., Childs, N. M., Meunier, J., \& White, C. 2008. Consumer perceptions of graded, graphic and text label presentations for qualified health claims. Crit. Rev. Food Sci. Nutr.. 48: 248-256. 


\section{INSIGHTS FOR NEW FUNCTIONAL FISH PRODUCTS}

793 Kaushik, A. K., \& Rahman, Z. 2014. Perspectives and dimensions of consumer innovativeness:

794

795

796

797

798

799

800

801

802

803

804

805

806

807

808

809

810

811

812

813

814

815

816
A literature review and future agenda. Journal of International Consumer Marketing, 26(3), 239-263.

Kearney, J. 2010. Food consumption trends and drivers Philos. Trans. R. Soc. Lond., B, Biol. Sci. 365, 2793-2807.

Kotilainen, L., Rajalahti, R., Ragasa, C., \& Pehu, E. 200). Health enhancing foods: Opportunities for strengthening the sector in developing countries. Discussion Paper 30. Washington, DC: World Bank.

Krueger, R. A., \& Casey M. A. 2014. Focus groups. A practical guide for applied research. Sage, London.

Krutulyte, R., Grunert, K. G., Scholderer, J., Lähteenmäki, L., Hagemann, K. S., Elgaard, P., Nielsen, B., \& Graverholt, J. P. 2011. Perceived fit of different combinations of carriers and functional ingredients and its effect on purchase intention. Food Qual. Prefer. 22: $11-16$.

Krutulyte, R., Scholderer, J., Hagemann, K., Grunert, G. K., Elgaard, P., Nielsen, B., \& Graverholt, J.P. 2008. Motivational factors for consuming omega-3 PUFAs: An exploratory study with Danish consumers. Appetite. 51: 137-147.

Lalor, F., Madden, C., McKenzie, K., \& Wall, P. G. 2011. Health claims on foodstuffs: a focus group study of consumer attitudes. J. Funct. Foods. 3: 56-59.

Lampila, P., Van Lieshout, M., Gremmen, B., \& Lahteenmaki, L. 2009. Consumer attitudes towards enhanced flavonoid content in fruit. Food Res. Int.42: 122-129.

Leathwood, P. D., Richardson, D. P., Sträter, P., Todd, P. M., \& van Trijp, C. M. 2007. Consumer understanding of nutrition and health claims: source of evidence. Br. J. Nutr. 98: 474-484. 


\section{INSIGHTS FOR NEW FUNCTIONAL FISH PRODUCTS}

817 Loose, S. M., Peschel, A., \& Grebitus, C. 2012. Quantifying effects of convenience and product packaging on consumer preferences and market share of seafood products. The case of oysters. Food Qual. Prefer. 28(2): 492-504.

Lyly, M., Roininen, K., Honkapaa, K., Poutanen, K., \& Lahteenmaki, L. 2007. Factors influencing consumers' willingness to use beverages and ready-to-eat frozen soups containing oat $\beta$-glucan in Finland, France and Sweden. Food Qual. Prefer. 18: 242255.

Mahmoudzadeh, M. A. R. Y. A. M., Motallebi, A. A., Hosseini, H. E. D. A. Y. A. T., Haratian, P., Ahmadi, H. A. M. E. D., Mohammadi, M. E. H. R. D. A. D., \& Khaksar, R. 2010. Quality assessment of fish burgers from deep flounder (Pseudorhombus elevatus) and brushtooth lizardfish (Saurida undosquamis) during storage at-18 ${ }^{\circ}$ C. Iran. J. Fish.

Mariotti, F., Kalonji, E., Huneau, J. F., \& Margaritis, I. 2010. Potential pitfalls of health claims from a public health nutrition perspective. Nutr. Rev. 68: 624- 638.

Martínez-González, M. A., Holgado, B., Gibney, M., Kearney, J., \& Martinez, J. A. 2000. Definitions of healthy eating in Spain as compared to other European Member States. Eur. J. Epidemiol. 16(6): 557-564.

Matak, K. E., Tahergorabi, R. \& Jaczynski, J. 2015. A review: Protein isolates recovered by isoelectric solubilization/precipitation processing from muscle food by-products as a component of nutraceutical foods. Food Res. Int. 77: 697-703.

Menrad, K. 2003. Market and marketing of functional food in Europe. J. Food Eng. 56: 181188.

Milner J.A., 2000 Functional foods: The US perspective, Am. J. Clin. Nutr. 71: 1654S-1659S 


\section{INSIGHTS FOR NEW FUNCTIONAL FISH PRODUCTS}

841

Neale, E. P., Nolan-Clark, D., Probst, Y. C., Batterham, M. J., \& Tapsell, L. C. 2012. Comparing attitudes to fish consumption between clinical trial participants and nontrial individuals. Nutr. Diet. 69(2): 124-129.

Nocella, G., \& Kennedy, O. 2012. Food health claims: What consumers understand? Food Policy. 37: 571-580.

O’Brien, G. M., Stewart-Knox, B. J., McKinley, A., de Almeida, M. D. V., \& Gibney, M. J. 2012. Perceived risk of metabolic syndrome and attitudes towards fat-modified food concepts among European consumers. Food Qual. Prefer. 23: 79-85.

Olsen, S. O. 2004. Antecedents of seafood consumption behavior: An overview. J. Aq. Food Prod. Technol. 13(3): 79-91.

Olsen, S. O., Scholderer, J., Brunsø, K., \& Verbeke, W. 2007. Exploring the relationship between convenience and fish consumption. A cross-cultural study. Appetite. 49(1): 84-91.

Olsen, S. O., Tudoran, A. A., Honkanen, P., \& Verplanken, B. (2016). Differences and Similarities between Impulse Buying and Variety Seeking: A Personality- based Perspective. Psychology \& Marketing, 33(1), 36-47.

Pieniak, Z., Verbeke, W., \& Scholderer, J. 2010. Health-related beliefs and consumer knowledge as determinants of fish consumption. J. Hum. Nutr. Diet. 23(5): 480-488.

Pieniak, Z., Verbeke, W., Scholderer, J., Brunsø, K., \& Olsen, S. O. 2007. European consumers' use of and trust in information sources about fish. Food Qual. Prefer. 18(8): 1050-1063.

Pothoulaki, M., \& Chryssochoidis, G. 2009. Health claims: Consumers' matters. J. Funct. Foods. 1(2): 222-228.

Powell, R. A., \& Single, H. M. 1996. Focus groups. Int. J. Qual. Health Care. 8 (5): 499-504. 


\section{INSIGHTS FOR NEW FUNCTIONAL FISH PRODUCTS}

865 Research and Markets 2014. Global Functional Food and Nutraceuticals Market (2014 - 2020)

866

867

868

869

870

871

872

873

874

875

876

877

878

879

880

881

882

883

884

885

886

887

888

889

- By Type (Foods, Beverages, Supplements); Benefits (Health and Wellness, Disease Prevention, Fitness, Beauty); Origin \& Ingredient.

Richardson, D. P. (2012). Preparing dossiers: Strength of the evidence and problems of proof, Proceedings of the Nutrition Society. 71, 127-140.

Roe, B., Levy, A. S., \& Deby, B. M. 1999. The impact of health claims on consumer search and product evaluation outcomes: Results from FDA experimental data. J.P.P.\&M. 18(1): 89-105.

Rortveit, A. W., \& Olsen, S. O. 2007. The role of consideration set size in explaining fish consumption. Appetite, 49(1), 214-222.

Rortveit, A. W., \& Olsen, S. O. 2009. Combining the role of convenience and consideration set size in explaining fish consumption in Norway. Appetite. 52(2): 313-317.

Siegrist, M., Stampfli, N., K**astenholz, H. 2008. Consumers' willingness to buy functional foods. The influence of carrier, benefit and trust. Appetite. 51: 526-529.

Siegrist, M., Hartmann, C., \& Keller, C. (2013). Antecedents of food neophobia and its association with eating behavior and food choices. Food Quality and Preference, 30(2), 293-298.

Sirò, I., Kápolna, E., Kápolna, B., Lugasi, A. 2008. Functional food. Product development, marketing and consumer acceptance. A review. Appetite. 51: 456-467.

Tahergorabi, R., Matak, K. E., \& Jaczynski, J. 2015. Fish protein isolate: Development of functional foods with nutraceutical ingredients. J Funct Foods. 18: 746-756.

Taşkaya, L., Cakli, S., Kişla, D., \& Kilinc, B. 2003. Quality changes of fish burger from rainbow trout during refrigerated storage. J Fish Aquat Sci. 20, 147-154.

Tudoran, A., Olsen, S. O., \& Dopico, D. 2009. The effect of health benefit information on consumers health value, attitudes and intentions. Appetite. 52(3), 568-579. 


\section{INSIGHTS FOR NEW FUNCTIONAL FISH PRODUCTS}

890 Tuorila, H., \& Cardello, A. V. 2002. Consumer response to an off-flavor in juice in the presence of specific health claims. Food Qual. Prefer. 13, 561-569.

Urala, N., \& Lähteenmäki, L. 2003. Reasons behind consumers' functional food choices. Nutr. Food Sci. 33, 148-158.

Varela, P., \& Ares, G. (2012). Sensory profiling, the blurred line between sensory and consumer science. A review of novel methods for product characterization. Food Research International. 48, 2: 893-908.

Verbeke, W., Sioen, I., Pieniak, Z., Van Camp, J., \& De Henauw, S. 2005. Consumer perception versus scientific evidence about health benefits and safety risks from fish consumption. Public health nutrition, 8(4), 422-429.

Verbeke, W. 2006. Functional foods: Consumer willingness to compromise on taste for health? Food Qual. Prefer. 17, 126-131.

Verbeke, W., \& Vackier, I. 2005. Individual determinants of fish consumption: application of the theory of planned behaviour. Appetite. 44(1), 67-82. behave as they do with respect to food safety and risk information. Analytica Chimica Acta, 586(1), 2-7.Verbeke, W., Vermeir, I., \& Brunsø, K. 2007. Consumer evaluation of fish quality as basis for fish market segmentation. Food quality and preference, 18(4), 651-661.

Wansink, B., Westgren, R. E., \& Cheney, M. M. 2005. Hierarchy of nutritional knowledge that relates to the consumption of a functional food. Nutrition. 21, 264-268.

912

Williams, P. G. 2005. Consumer understanding and use of health claims for foods. Nutr. Rev.

\section{Footnotes}

